Ĭgdır Üniversitesi Fen Bilimleri Enstitüsü Dergisi, 11(Özel Sayı): 3539-3545, 2021

Journal of the Institute of Science and Technology, 11(Special Issue): 3539-3545, 2021

\begin{tabular}{lrr} 
& ISSN: $2146-0574$, eISSN: 2536-4618 \\
\hline Tarla Bitkileri/ Field Crops & DOI: 10.21597/jist.1027219 \\
Geliş tarihi / Received: 22.11 .2021 & Kabul tarihi / Accepted: 08.12.2021
\end{tabular}

Atıf İçin: Tosun B, Karadoğan T, Şanlı A, 2021. Apiaceae Familyasına Dahil Bazı Echinophora Türlerinin Çimlenme Özelliklerinin Belirlenmesi. Iğdır Üniversitesi Fen Bilimleri Enstitüsü Dergisi, 11(Özel Sayı): 3539-3545.

To Cite: Tosun B, Karadoğan T, Şanlı A, 2021. Determination of Germination Characteristics of Some Echinophora Species Included in Apiaceae Family. Journal of the Institute of Science and Technology, 11(Special Issue): 3539-3545.

\title{
Apiaceae Familyasına Dahil Bazı Echinophora Türlerinin Çimlenme Özelliklerinin Belirlenmesi
}

$$
\text { Bekir TOSUN }{ }^{1 *} \text {, Tahsin KARADOĞAN }{ }^{2} \text {, Arif ŞANLI }{ }^{2}
$$

ÖZET: Bu araştırma, doğal olarak yetişen Echinophora tournefortii Jaub. \& Spach., Echinophora tenuifolia L. subsp sibthorpiana (Guss) Tutin ve Echinophora trichophylla J.E.Smith (Endemik) türlerinin çimlenme özelliklerinin belirlenmesi amacıyla yürütülmüsstür. Doğal yetişme alanlarından 2019 yılında toplanan olgunlaşmış tohum örneklerinde X-ray çekimleri, GA3 (0, 250, 500 ve 1000 ppm) uygulamaları, soğuk katlama (30, 60, 90 ve 120 gün) uygulamaları ile sonbahar ve ilkbahar ekimleri yapılmıştır. X ray çekimlerinde $E$. tournefortii, E. tenuifolia L. subsp sibthorpiana ve E. trichophylla tohumlarının sırası ile \% 9.8, \% 94.1 ve \% 83.8 oranında tohum doluluk oranında sahip olduğu belirlenmiştir. GA3 uygulamaları Echinophora türlerinin çimlenmesi üzerine herhangi bir etki göstermemiştir. Farklı sürelerde yapılan soğuk katlama uygulamalarında $E$. tenuifolia L. subsp sibthorpiana türünde 120 gün süre ile katlamada bırakılan tohumların \% 20.7'sinde çimlenme meydana gelmiştir. Herhangi bir ön işlem uygulanmadan sonbaharda yapılan ekimlerde E. tenuifolia L. subsp sibthorpiana tohumlarının \% 58.7'si, E. trichophylla tohumlarının ise \% 9.3'ü, ilkbaharda yapılan ekimlerde ise E. tenuifolia L. subsp sibthorpiana tohumlarının \% 14.0'ü, E. trichophylla tohumlarının ise \% 8.3'ü çimlenmiştir. Çalışmada kullanılan Echinophora türlerine ait tohumların oda koşullarında çimlenmediği ve dormansiye sahip olduğu belirlenmiştir.

Anahtar Kelimeler: Apiaceae, Echinophora, Soğuk Katlama, Çimlendirme, X-ray çekimleri

\section{Determination of Germination Characteristics of Some Echinophora Species Included in Apiaceae Family}

ABSTRACT: This study was conducted to determine the germination characteristics of the of Echinophora tournefortii Jaub. \& Spach., Echinophora tenuifolia L. subsp sibthorpiana (Guss) Tutin and Echinophora trichophylla J.E. Smith (Endemic) species which are grown naturally. The ripe seed samples were collected in 2019 from natural habitats and X-ray shots, GA3 (0, 250, 500 and $1000 \mathrm{ppm})$ applications, cold stratification (30, 60, 90 and 120 days) applications, autumn and spring planting were made. Seed filling ratios of E. tournefortii, E. tenuifolia L. subsp sibthorpiana and E. trichophylla were determined as $9.8 \%, 94.1 \%$ and $83.8 \%$, respectively in the X-ray shots. GA3 applications did not show any effect on the germination of Echinophora species. Cold stratification applications, made at different times, germination occurred in $20.7 \%$ of the seeds left in stratification for 120 days only in E. tenuifolia L. subsp sibthorpiana. In the autumn sowing, without any pre-treatment application, E. tenuifolia L. subsp sibthorpiana until $58.7 \%$ of the seed, while $3.9 \%$ of E. trichophylla seed, in the spring sowing, $14.0 \%$ of E. tenuifolia L. subsp sibthorpiana seeds and $8.3 \%$ of E. trichophylla seeds were germinated. It was determined that the seeds of the Echinophora species used in the study did not germinate under room conditions and had dormancy.

Keywords: Apicaceae, Echinophora, Cold stratification, Germination, X-ray shots

\footnotetext{
${ }^{1}$ Bekir TOSUN (Orcid ID: 0000-0002-2470-3865), Burdur Mehmet Akif Ersoy Üniversitesi, Tarım, Hayvancılık ve Gıda Araştırmaları Uygulama ve Araştırma Merkezi, Burdur, Türkiye

2 Tahsin KARADOĞAN (Orcid ID: 0000-0002-3422-8295), Arif ŞANLI (Orcid ID: 0000-0002-5443-2082), Isparta Uygulamal1 Bilimleri Üniversitesi, Ziraat Fakültesi, Tarla Bitkileri Bölümü, Isparta, Türkiye

*Sorumlu Yazar/Corresponding Author: Bekir TOSUN, e-mail: btosun@mehmetakif.edu.tr

Makale 15-17 Kasım 2021 tarihlerinde Iğdır’da düzenlenen “Türkiye 7. Tohumculuk Kongresi” sözlü olarak sunulmuştur.

Bu çalışma "Göller Yöresinde Yayılış Gösteren Apiaceae Familyasına Ait Bazı Bitki Türlerinin Ekonomik Değerleri ile Kültüre Alma Potansiyellerinin Belirlenmesi” Doktora tezinden üretilmiştir
} 


\section{GíRiș}

Echinophora cinsi ülkemizde üç tanesi endemik olmak üzere altı farklı türü bulunmaktadır (Davis 1972). Çalışmada ise bölgede doğal yayılış gösteren E. tournefortii, E. tenuifolia subsp sibthorpiana ve E. trichophylla (Endemik) türleri ele alınmıştır. Bu türler arasında yer alan E. tenuifolia L. subsp sibthorpiana alt türü halka arasında "çördük, çörtük, tarhana otu" gibi isimlerle bilenmekte olup farklı illerde turşu, baharat ve taze olarak tüketilmektedir ( Doğan ve ark. 2014). Tür halk hekimliğinde herba kısımlarının infizyonu ve dekoksiyonu kullanılarak soğuk algınlığında, iştah artırıcı, sindirim düzenleyici ve ağrı giderici olarak kullanılmaktadır (Bulut ve ark. 2014).

Çalışmada yer alan türlerden E. tenuifolia subsp sibthorpiana yöre halkı tarafından doğadan toplanarak tüketilmekte, diğer türlerin ise kullanım amacı ve alanlarının bilinmemesi nedeniyle faydalanılmamaktadır. Belirli habitatlarda gelişen türlerin doğadan toplanarak değerlendirilmesi, bu türlerin ileriki dönemlerde popülasyonlarının azalmasına hatta yok olma tehlikesine yol açabileceği düşünülmektedir. Bu nedenle, araştırmada türlerin doğadan toplanmaları yerine etken maddenin standart üretimine yönelik kültüre alma çalışmalarının yapılması hedeflenmiştir. Ele alınan türler genellikle çok yıllık otsu türler olup, tohumlarında büyük oranda çimlenme problemleri bulunmaktadır. Türlerin geliştiği habitatlarda tohumların bazı hastalık ve zararlılar nedeniyle ortaya çıkan çimlenme problemlerinin dışında, tohumlarda içsel ve dışsal dormansinin bulunması türlerin kültüre alma çalışmalarını daha zorlaştırmaktadır. Değişen iklim koşulların bitkilerin yaşaması için oldukça zorlaştırmakta, bu durum ise bitkilerin hayatta kalmaları ve nesillerini devam ettirebilmeleri için çeşitli adaptasyon yeteneklerini geliştirmesi için kritik önem taşımaktadır. Türlere bağlı olarak göstermiş oldukları adaptasyon yeteneği ise oldukça farklılık göstermektedir. Bitki türleri genellikle böyle durumlarda yaşamsal faaliyetlerini asgari düzeye indirmek için dormansi (uyku) halinde geçmektedir. Bazı türler dormansi durumunu soğan, spor, rizom veya tohum olarak geçirebilmektedir. Tohum dormansisi bitkinin en savunmasız yaşam evrelerinde biri olup ekolojik koşullar ile arasındaki ilişkiyi düzenleyerek çimlenmenin sağlanması için kritik önem taşımaktadır. Tohum bu hassas dengeyi farklı morfolojik, fizyolojik ve anatomik mekanizmalar vasıtası ile gerçekleştirmektedir. Dormansi, tohumun çimlenme zamanını kontrol eden ve genetik meşeli engelleme mekanizması olarak işlev görmektedir. $\mathrm{Bu}$ durum tohum uygun olmayan durumlarda çimlenmesini engelleyerek türün neslinin devamlılığına imkan sağlamaktadır. Willis ve ark (2014) dormansi sebebi ile tohumun çimlenememesi, türün yeni lokasyonlarda uygun dönemlerde ve farklı iklim koşullarında yeni bir popülasyon oluşturabileceğini bildirmiştir (Linkies ve ark., 2010). Bu gibi zorluklara ek olarak türlerin çok sayıda tohum üretmelerine karşılık tohumlarının canlılık oranlarının düşük olması da önemli bir sorun olarak karşımıza çıkmaktadır. $\mathrm{Bu}$ nedenlerle, ele alınan türlerde tohumların canlılık durumları, doğal habitatlarında karşılaştıkları hastalık ve zararlıların etkileri ve çimlenme oranları belirlenerek, çimlenmeyen ya da çimlenme oranı düşük olan tohumlarda çimlenmenin teşvik edilmesine yönelik katlama ve kimyasal uygulamaları yapılarak kültüre alma çalışmalarının başlatılması hedeflenmiştir.

\section{MATERYAL VE METOT}

Araştırma 2017-2018 yıllarında Isparta Uygulamalı Bilimler Üniversitesi, Ziraat Fakültesi, Tarla Bitkileri laboratuvarlarda yürütülmüştür. Çalışma kapsamında bölgede daha önce yapılan TUBİTAK 1130284 proje sonucunda yayılış alanları belirlenen türlerin lokasyon bilgilerinden faydalanılarak meyve örnekleri sarı olum dönemi sonunda toplanarak muhafaza edilmektedir. 
Çizelge 1.Araştırmada ele alınan türlere ait herbaryum kodları ve lokalite bilgileri

\begin{tabular}{ccc}
\hline Türler & Gül Herbaryumu Kodları & Lokaltite/Rakım \\
\hline Echinophora tournefortii Jaub. \& Spach. & GUL 63.7.2.5 & Burdur: Yeşilova/ $1236 \mathrm{~m}$ \\
Echinophora tenuifolia L. & 63.7 .5 .1 .2 & Isparta: Merkez/ 1010 m \\
subsp sibthorpiana (Guss) Tutin & GUL 63.7.4.1 & Isparta: Sav kasabas1/981 1 \\
\hline Echinophora trichophylla J.E.Smith (Endemik &
\end{tabular}

Çizelge 1. verilen türler Prof. Dr. Hasan Özçelik tarafından teşhis edilerek Süleyman Demirel Üniversitesi, Fen Edebiyat Fakültesi, Biyoloji Bölümü, GUL Herbaryum’undan yayınlanmaktadır.

\section{Tohumların çimlenme özellikleri}

Araştırmada türlere ait tohumların fiziksel özelliklerinden (tohum rengi, iriliği, ağırlığı, böcek zararı vb.) faydalanılarak seçim işlemi gerçekleştirilmiştir. Bu seçimlerden elde edilen tohumlar ise materyal olarak kullanılmıştır. Türlere ait tohumlarında canlılık durumlarının ve çimlenme durumlarının belirlenmesi amacıyla canlılık testi ve çimlendirme çalışmaları yapılmıştır. Tohumlar fungal enfeksiyon barındırma riski yüksek olmaları nedeniyle çimlendirme çalışmalarına alınmadan önce \% 80'lik thiram etken maddeli Pomarsol Forte ile muamele edilmiştir.

\section{X-Ray çekimleri}

X-Ray cihazında (UltraFocus X-ray Imaging System) her bir türden seçilen 100'er adet tohum 3 tekrarlamalı olarak X-ray çekimleri gerçekleştirilmiştir. Elde edilen görüntülerden faydalanılarak dolu tohum sayısı, toplam tohum sayısına oranlanarak toplam doluluk oranı (\%) hesaplanmıştır.

\section{Soğuk katlama uygulamaları}

Her bir türe ait 1200 'er adet tohum $4 \pm 1{ }^{\circ} \mathrm{C}$ sicaklıkta $30,60,90$ ve 120 gün süre ile perlit içerisinde katlamaya alınmıştır. Her biri 300 adet tohum içeren gruplar, delikli plastik kâseler içerisinde, bir kat nemli perlit bir kat tohum olacak şekilde katlama işlemi yapılmıştır. Soğuk katlamadan sonra tohumlar viyollere ekilerek oda koşullarında çimlenmeye bırakılmıştır.

\section{Kültüre alma çalışmaları}

Çalışmanın bu aşaması türlere ait tohumların dış ortam şartlarında viyol içerisinde fide gelişimlerinin belirlenmesi ve fidelerin arazi koşullarında gelişme durumlarının belirlenmesine yönelik olarak tohumların viyollere sonbahar ve ilkbahar ekimleri olmak üzere 2 aşamalı olarak yürütülmüştür. $\mathrm{Bu}$ çalışmada her türe ait tohumlar irilik, sertlik, şekil, renk ve boş-doluluk özellikleri dikkate alınarak seçilmiştir.

\section{Sonbahar ekimlerinde fide gelişimi (\%)}

Her bir türe ait tohumlar içerisinde 3:1 oranında pertlit/torf karşımı içeren (24'lü viyoler) her bir göze 4 adet tohum gelecek şekilde 13/11/2017 tarihinde ekilmiştir. Ekimi yapılan viyoller açık alana alınmış ve sürekli nemli tutulmuştur. Viyollerde fide gelişimi 15/04/2018 tarihine kadar takip edilmiş ve fide gelişim oranları \% olarak belirlenmiştir. Elde edilen fideler ise arazi koşullarına şaşırtılmıştır.

\section{İkbahar ekimleri}

Her bir türe ait tohumlar içerisine 3:1 oranında pertlit/torf karşımı içeren (24'lü viyoller) her bir bölümde 4 adet tohum gelecek şekilde 17/03/2018 tarihinde ekilmiştir. Viyollerde fide gelişimi 17/06/2018 tarihine kadar takip edilmiş ve fide gelişim oranları \% olarak hesaplanmıştır. Elde edilen fideler ise arazi koşullarına şaşırtılmıştır.

İlkbahar ve sonbahar ekimlerinde fide çıkışları haftalık olarak takip edilmiş ve her türün çimlenme oranları belirlenmiştir. Çıkış yapan türlerde fide gelişiminin devam etmesi sağlanarak, fidelerin yeterli 
büyüklüğe ulaşması halinde toprağa şaşırtma yapılmıştır. Bu aşamada fidelerin gerekli bakım işlemleri (sulama, yabancı ot mücadelesi, gübreleme gibi) yapılmış ve bitki gelişimleri takip edilmiştir.

Her bir türe ait fidelerin koleksiyon bahçesine dikimlerinde dikim normları, bitkilerin habitüsleri (bitki boyu, dallanma şekli, kapladığı alan vb.) dikkate alınarak belirlenmiştir. Uzun boylu ve çok dallanan türlerde sıra arası ve üzeri mesafeler geniş (70x50 $\mathrm{cm}$ sıra arasi), kısa boylu ve az dallanan türlerde ise dar (50x30 cm sıra arası) bırakılmıştır. Apiaceae familyasından kültürü yapılan türlerde (kimyon, anason, vb.) önerilen gübreleme programı dikkate alınarak besin maddesi ilavesi yapılmıştır. Yabancı otlar ile elle mücadele yapılmıştır. Her bir türün toplandığı alanın özellikleri (su kenarları ya da kayalık, kıraç alanlar gibi) dikkate alınarak su ihtiyacı olduğu düşünülen türlerde sulama işlemi yapılmıştır.

\section{GA3 uygulamaları}

Her bir türe ait 25 adet tohum 3 tekerrürlü olacak şekilde $0,250,500$ ve 1000 ppm GA 3 solüsyonlarında 24 saat süre ile oda sicaklığında bekletilmiştir. Uygulama yapılan tohumlar saf sudan geçirildikten sonra petri kaplarında ISTA standartlarına göre oda sıcaklı̆̆ında aydınlık ortamda çimlenmeye bırakılmıştır. Çimlenme için radikulanın belirgin derecede (2 mm) testadan çıkmış olması esas kabul edilmiştir (Ünal vd., 2004). Uygulamaların yapılmasından sonra her gün çimlenen tohum sayıları alınmış ekimlerden 45 gün sonra tüm petrilerde toplam çimlenen tohum sayımları yapılarak çimlenme yüzdesi (\%) belirlenmiştir.

Çalışma tesadüf parselleri deneme deseninde 3 tekrarlı olarak kurulmuş olup elde edilen verilerin ortalamaları ve standart sapmaları hesaplanmıştır.

\section{BULGULAR VE TARTIŞMA}

X ray çekimleri sonucunda türlere ait seçilen tohumların $E$. tournefortii türünde $\% 9.8 \pm 1.5$ 'sinin, E. tenuifolia L. subsp sibthorpiana' da \% 94.1 \pm 1.0 ve E. trichophylla 'da \% 83.8 \pm 1.0 'nun dolu olduğu belirlenmiştir.

Çalışmada türlerin çimlenme durumlarını belirlemek amacıyla farklı konsantrasyonlarda $\mathrm{GA}_{3}$ uygulamaları $(0,250,500$ ve $1000 \mathrm{ppm})$ yapılmıştır. Uygulama yapıldıktan sonra oda koşullarında 45 gün boyunca bekletilen türlere ait tohumlarda ise hem farklı konsatrasyonlarındaki $\mathrm{GA}_{3}$ uygulamalarında hem de kontrol gruplarında çimlenme olmadığı saptanmıştır.

Çizelge 2. Farklı sürelerde gerçekleştirilen soğuk katlama uygulamalarının çimlenme oranına etkisi (\%)

\begin{tabular}{ccccc}
\hline Katlama süresi (gün)/Çimlenme oranı (\%) & $\mathbf{3 0}$ & $\mathbf{6 0}$ & $\mathbf{9 0}$ & $\mathbf{1 2 0}$ \\
\hline E. tournefortii & $0.0 \pm 0.0$ & $0.0 \pm 0.0$ & $0.0 \pm 0.0$ & $0.0 \pm 0.0$ \\
E. tenuifolia L. subsp sibthorpiana & $0.0 \pm 0.0$ & $0.0 \pm 0.0$ & $8.3 \pm 1.2$ & $20.7 \pm 2.1$ \\
E. trichophylla & $0.0 \pm 0.0$ & $0.0 \pm 0.0$ & $0.0 \pm 0.0$ & $0.0 \pm 0.0$ \\
\hline
\end{tabular}

Farklı sürelerde $\left(30,60,90\right.$ ve 120 gün) $+4{ }^{\circ} \mathrm{C}$ gerçekleştirilen soğuk katlama uygulamaları sonucunda E. tournefortii ve E. trichophylla türlerinin tohumlarında çimlenme gözlenmemiştir. Ancak E. tenuifolia subsp. sibthorpiana tohumlarında soğuk katlama uygulamalarının kısmen etkili olduğu belirlenmiştir. Soğuk katlama uygulamasının 90. gününde tohumların \% 8.3'i çimlenirken, katlamanın 120. gününde ise tohumların \% 20.7'sinde çimlenme meydana gelmiştir (Çizelge 2).

Çizelge 3. İlkbahar ekimleri sonucunda tohum çimlenme oranı (\%)

\begin{tabular}{cccccc}
\hline Taksonlar & 5. hafta & 6. hafta & 7. hafta & 8. hafta & 9. hafta \\
\hline E. tournefortii & $0.0 \pm 0.0$ & $0.0 \pm 0.0$ & $0.0 \pm 0.0$ & $0.0 \pm 0.0$ & $0.0 \pm 0.0$ \\
E. tenuifolia L. subsp sibthorpiana & $0.7 \pm 0.3$ & $8.0 \pm 1.0$ & $12.3 \pm 1.5$ & $14.0 \pm 2.0$ & $14.0 \pm 2.0$ \\
E. trichophylla & $1.7 \pm 0.6$ & $2.3 \pm 0.6$ & $4.0 \pm 1.0$ & $7.2 \pm 2.0$ & $8.3 \pm 1.0$ \\
\hline
\end{tabular}


Herhangi bir uygulama yapılmaksızın mart ayında viyollere ekilen tohumların haziran ayına kadar çimlenme durumları takip edilmiştir. E. trichophylla türünün tohumlarının ilkbaharda ekimleri sonucunda çimlenme belirlenememiştir (Çizelge 2.). E. tenuifolia subsp. sibthorpiana tohumlarının İlkbaharda ekimleri gerçekleştirilen tohumların çimlenmeleri ekimden 5 hafta sonra başlayarak (\% 0.7 ) ekimden 8 hafta sonrasına kadar çıkış oranlarında artış meydana gelmiştir. Ekimlerden 8 hafta sonra ise çıkış oranı sabit kalarak tohumların \% 14.0'sinde çimlendiği tespit edilmiştir. E. trichophylla tohumlarının İlkbaharda viyollere yapılan ekimleri sonucunda ise, ekimden 5 hafta sonra tohumların \% 1.7'sinde çimlenme belirlenirken ekim zamanın ilerlemesi bağlı olarak çimlenme oranlarında artış meydana gelerek ekimlerden 9 hafta sonra bu oran \% 8.3 olarak belirlenmiştir (Çizelge 3.)

Çizelge 4. Sonbaharda ekilen tohumlara ait çimlenme oranı

\begin{tabular}{cccccc}
\hline Taksonlar & 13. hafta & 14. hafta & 15. hafta & 16. hafta & 17. hafta \\
\hline E. tournefortii & $0.0 \pm 0.0$ & $0.0 \pm 0.0$ & $0.0 \pm 0.0$ & $0.0 \pm 0.0$ & $0.0 \pm 0.0$ \\
E. tenuifolia L. subsp sibthorpiana & $16.0 \pm 1.0$ & $43.0 \pm 2.6$ & $56.0 \pm 2.0$ & $58.7 \pm 1.5$ & $58.7 \pm 1.5$ \\
E. trichophylla & $0.0 \pm 0.0$ & $1.7 \pm 0.6$ & $6.3 \pm 1.3$ & $9.3 \pm 0.6$ & $9.3 \pm 0.6$ \\
\hline
\end{tabular}

Türlere ait tohumlara herhangi bir uygulama yapılmaksızın kasım ayında gerçekleştirilen ekimler sonucunda E. tournefortii tohumlarında çimlenme meydana gelmemiştir. E. tenuifolia subsp. sibthorpiana tohumlarının sonbaharda viyollere ekimleri gerçekleştirilen tohumları ekimden 13 hafta sonra \% 16.0'sı çıkış yaparken, bu oran ekimden 14 hafta sonra \% 43.0, 15 hafta sonra ise \% 56.0 olarak meydana gelmiştir. Ekimler 16 hafta sonra ise türün tohumlarının çıkış oranı sabit kalarak \% 58.7'sinin çıkış yaptığı belirlenmiştir. Sonbaharda E. trichophylla tohumlarına herhangi bir uygulama yapılmadan viyollere ekimi yapılan tohumlarının ekimden 14 hafta sonra çıkış yapmaya başladığ 1 ve ekimden 16 hafta sonra meyvelerin \% 9.3'ü çıkış yaptığı tespit edilmiştir. Ekim zamanın ilerlemesi bağlı olarak çıkış oranında herhangi bir artış söz konusu olmadığı görülmüştür (Çizelge 4).

Martin (1946) embriyonun büyüklüğüne, şekline endosperm ve pozisyonuna ve diğer depo dokularına bağlı olarak bitki türlerini; linear eksen (LA), bazal embriyo (B; B1-B4), yapraks1 eksen (FA; FA1-FA4), periferal embriyo (P), minyatür eksen (MA), olarak gruplandırmıştır. Finch-Savage ve Leubner-Metzger, 2006, göre Apiaceae familyasına ait tohumların bazal gelişmemiş embriyoya sahip olduğunu bu ek olarak fizyolojik veya morfofizyolik dormansiye sahip olduğunu bildirmiştir. Tohumların morfofizyolojik dormansiye sahip olmaları dormansinin fizyolojik bir bileşeni ile yetersiz gelişim gösteren bir embriyo sahip olduğunu vurgulamaktadır. Bu nedenle, tohumların çimlenmeleri için dormansi kırmada ön muamelesine ihtiyaç duyarlar (Baskin ve Baskin, 2004). Tohumlara, bazı durumlarda sicak veya soğuk katlama yapılaması GA uygulamasının yerini alarak dormansinin kırılmasında yardımcı olabilmektedir (Finch-Savage ve Leubner-Metzger, 2006). Morfofizyolojik dormansi olan tohumlarda, embriyo büyümesi (radikül ortaya çıkışı), morfolojik dormansi olan tohumlardan çok daha uzun bir süre gerektirir. (Baskin ve Baskin, 2004). Bazı durumlarda ise katlama işlemlerinin GA uygulamalarının yerinin alamayacağı bildirilmiştir (Baskin ve Baskin 2003). Nitekim araştırma sonucunda $\mathrm{GA}_{3}$ uygulamalarının türlerin çimlenmesi üzerine etkisinin olmadığı belirlenirken, soğuk katlama uygulamasından ve sonbahar ekimleri sonucunda uzun süre düşük sıcaklığa maruz kalan tohumların daha yüksek çimlenme oranına sahip olduğu belirlenmiştir.

\section{SONUÇ}

E. tournefortii tohum doluluk oranının düşük olması çimlenme durumlarını oldukça etkilemiştir. Çimlenmeyi iyileştirici uygulamalar arasında yer alan farklı konsantrasyonlardaki $\mathrm{GA}_{3}$ ve soğuk katlama sonucunda tohumların bazıları çimlenmemiştir. Bunun yanı sıra sonbahar ve ilkbaharda viyollere ekilen 
tohumlarda çimlenmeye rastlanamamıştır. Türün çoğaltılabilmesi için ilerleyen çalışmalarda farklı çimlendirmeyi iyileştirici uygulamaların denenmesi gerektiği düşünülmektedir. E. tenuifolia subsp sibthorpiana' yı kültüre almaya yönelik yapılan çimlenmeyi iyileştirici uygulamalar arasında yer alan $\mathrm{GA}_{3}$ uygulamalarında tohumlar çimlendirilemezken, soğuk katlama uygulaması ile tohumların bir kısmında çimlenme meydana gelmiştir. Tohumların herhangi bir uygulama yapılmaksızın viyollere ekimleri gerçekleştirilen türün sonbahar ekimlerinde daha yüksek çimlenme oranı tespit edilmiştir. Türün tohumlarından elde edilen fidelerin arazi koşullarına aktarılması sonucunda fidelerin yaklaşı \% 85 oranında fide tutumu sağlanmıştır. Türün fideleri dikildikten sonraki yıl yaklaşı \% 70'i sapa kalkarak meyve bağlamıştır. E. trichophylla (endemik) türüne ait seçilen tohumların büyük oranda dolu olduğu belirlenmiştir. Ancak soğuk katlama ve $\mathrm{GA}_{3}$ uygulamaları sonucunda çimlenme meydana gelmemiştir. Sonbahar ve ilkbahar ekimleri sonucunda ise türe ait tohumların \% 10'nundan azı çimlenmiştir. Bu ekimler sonucunda elde edilen fidelerin yaklaşık \% 40'lik kısımlık fideleri tutmuştur. Dikimlerden sonraki yıl fidelerin yaklaşık \% 5'lik kısmında sapa kalma meydana gelmiş fakat tohum bağlayamamıştır. Çalışmada yapılan çimlenmeyi iyileştirici uygulamalara rağmen meyvelerin çimlenme oranlarının düşük olması türün meyvelerin çimlendirilebilmesi için farklı uygulamalardan faydalanarak tekrardan çimlenme çalışmalarının yapılması gerektiği düşüncesini doğurmaktadır.

Sonuç olarak türlerin tohumlarında farklı çimlenmeyi iyileştirici uygulamalardan faydalanarak çimlenme oranının artırabileceği düşünülmektedir.

\section{TEŞEKKÜR}

Çalışmada tür teşhislerine yapmış olduğu katkıdan dolayı Prof. Dr. Hasan ÖZÇELiK' e teşekkür ederiz. Araştırma “Göller Yöresi’nde Yayılış Gösteren Apiaceae Familyasına ait Bazı Bitki Türlerinin Ekonomik Değerleri ile Kültüre Alma Potansiyellerinin Belirlenmesi” konulu Doktora tezinden üretilmiştir.

\section{Çıkar Çatışması}

Makale yazarları aralarında herhangi bir çıkar çatışması olmadığını beyan ederler.

\section{Yazar Katkısı}

Yazarlar makaleye eşit oranda katkı sağlamış olduklarını beyan eder.

\section{KAYNAKLAR}

Baskin JM, Baskin CC, 2004. A classification system for seed dormancy. Seed Science Research, 14: 116.

Baskin JM, Baskin CC, 2003. Classification, biogeography, and phylogenetic relationships of seed dormancy., In: Smith RD, Dickie JB, Linnington SH, Pritchard HW, Probert RJ, Editors. Seed conservation: Turning science into practice. Kew: Royal Botanic Gardens; p. 517-544.

Bulut G, Tuzlacı A, Doğan A, Şenkardeş İ, 2014. An ethnopharmacological review on the Turkish Apiaceae species. İstanbul Journal of Pharmacy, 44(2): 163-179.

Davis H, 1972. Flora of Turkey and the East Aegean Islands. Vol. 4, p 309, University Press, Edinburgh.

Doğan A, Bulut G, Tuzlacı E, Şenkardeş İ, 2004. A review of Edible Plants on the Turkish Apiaceae Species. İstanbul Journal of Pharmacy, 44(2): 251-262.

Finch-Savage WE, Footitt S, 2017. Seed dormancy cycling and the regulation of dormancy mechanisms to time germination in variable field environments. Journal of Experimental Botany, 68: 843-856.

Finch-Savage WE, Leubner-Metzger G, 2006. Seed dormancy and the control of germination. New Phytol, 171: 501-523. 
Linkies A, Graeber K, Knight C, Leubner-Metzger G, 2010. The evolution of seeds. New Phytologist, 186: 817-831.

Martin AC, 1946. The comparative internal morphology of seeds. The American Midland Naturalist, 36: 513-660.

Willis CG, Baskin CC, Baskin JM, Auld JR, Venable DL, Cavender-Bares J, NESCent Germination Working Group. 2014. The evolution of seed dormancy: environmental cues, evolutionary hubs, and diversification of the seed plants. New Phytologist, 203: 300-309. 